
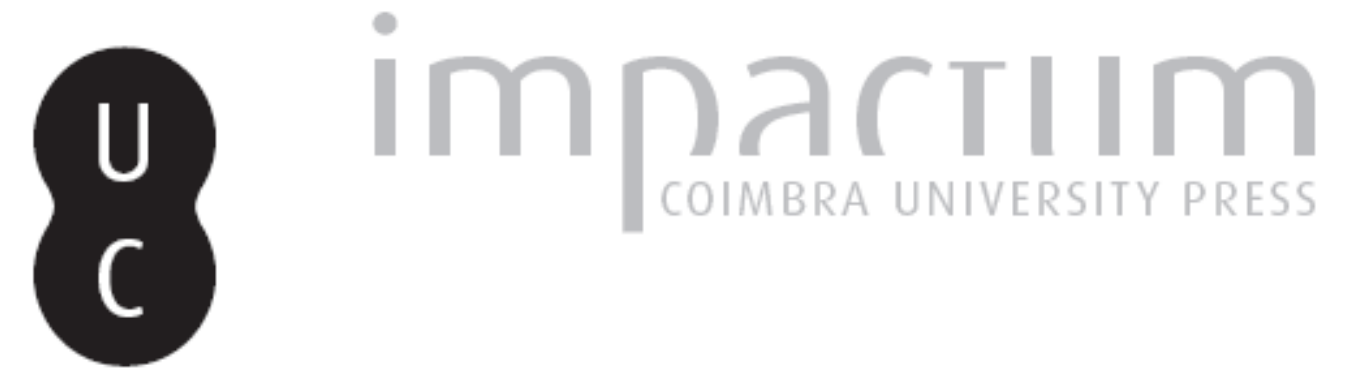

O preço da crise: níveis de vida no Portugal seiscentista

Autor(es): $\quad$ Faísca, Carlos Manuel

Publicado por: Centro de História da Sociedade e da Cultura

URL persistente:

URI:http://hdl.handle.net/10316.2/39432

DOI:

DOI:http://dx.doi.org/10.14195/1645-2259_12_11

Accessed : $\quad$ 26-Apr-2023 05:18:50

A navegação consulta e descarregamento dos títulos inseridos nas Bibliotecas Digitais UC Digitalis, UC Pombalina e UC Impactum, pressupõem a aceitação plena e sem reservas dos Termos e Condições de Uso destas Bibliotecas Digitais, disponíveis em https://digitalis.uc.pt/pt-pt/termos.

Conforme exposto nos referidos Termos e Condições de Uso, o descarregamento de títulos de acesso restrito requer uma licença válida de autorização devendo o utilizador aceder ao(s) documento(s) a partir de um endereço de IP da instituição detentora da supramencionada licença.

Ao utilizador é apenas permitido o descarregamento para uso pessoal, pelo que o emprego do(s) título(s) descarregado(s) para outro fim, designadamente comercial, carece de autorização do respetivo autor ou editor da obra.

Na medida em que todas as obras da UC Digitalis se encontram protegidas pelo Código do Direito de Autor e Direitos Conexos e demais legislação aplicável, toda a cópia, parcial ou total, deste documento, nos casos em que é legalmente admitida, deverá conter ou fazer-se acompanhar por este aviso. 
evista de História da Sociedade e da Cultura

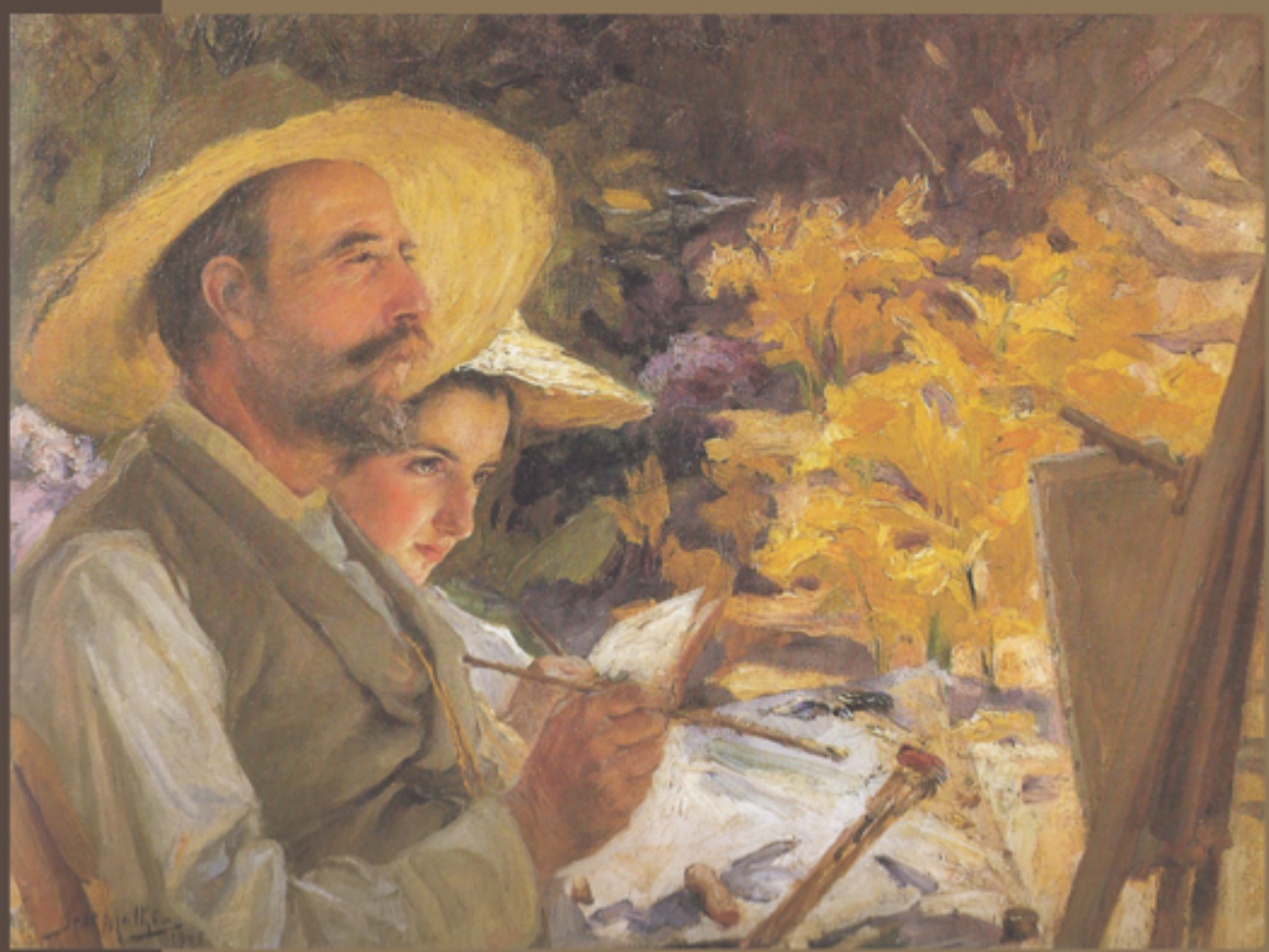

Centro de História da Sociedade e da Cultura Universidade de Coimbra 


\title{
O preço da crise: níveis de vida no Portugal seiscentista
}

\author{
Carlos Manuel Faísca \\ Instituto de Ciências Sociais / Universidade de Lisboa \\ cmsaff@gmail.com \\ Texto recebido em /Text submitted on: 29/10/2011 \\ Texto aprovado em /Text approved on: 03/12/2011
}

\section{Resumo/Abstract:}

Este artigo aborda a evolução do nível de vida em Portugal no século XVII, centrando-se em dois casos específicos, designadamente, Lisboa e Coimbra, a partir do cruzamento entre um índice de preços e os salários de trabalhadores especializados da construção civil e de trabalhadores indiferenciados. Começamos por uma breve caracterização do panorama político e económico quer a nível nacional, quer das duas cidades alvo deste estudo, para de seguida apresentarmos os resultados das nossas investigações. Por último, demonstramos que os níveis de vida caíram em ambas as cidades de forma bastante semelhantes, sugerindo a integração dos dois mercados e colocando Portugal junto do grupo de países europeus em que os níveis de vida baixaram neste período, por oposição às economias liderantes como, por exemplo, as de Inglaterra e a Holanda.

This article studies the evolution of the living standards in Portugal during the seventeenth century, from the analysis of two specific cases, the cities of Lisbon and Coimbra. To find this we used a Consumer Price Index and Wages of both skilled and unskilled workers. First, we briefly approach the political and economic characterization of Portugal and of the two cities that we studied in, and then we present the results of our research. Finally, we demonstrate that the living standards fell in both cities with a similar pattern, suggesting the market integration and locating Portugal between the group of European countries where this indicator fell during this century, opposing the lidding economies such as England and the Netherlands.

Palavras chave/Keywords:

Níveis de vida; Lisboa; Coimbra; Século XVII.

Living Standards; Lisboa; Coimbra; XVII century. 


\section{Introdução ${ }^{1}$}

O século XVII tem sido apontado para Portugal como um período de crise económica. De acordo com alguns estudos recentes ${ }^{2}$, foi durante o início da época moderna que o Nordeste Europeu - sobretudo Inglaterra e Holanda - se começou a afastar do resto da Europa em termos de crescimento económico, com repercussões visíveis ao nível da urbanização, produtividade e crescimento dos níveis de vida, criando as condições ideais para o advento da Revolução Industrial ${ }^{3}$. Pelo contrário, na Europa Central e do Sul, o rendimento per capita decaiu e, dessa forma, as condições para o desenvolvimento económico estiveram ausentes.

O presente trabalho procura compreender, por um lado, quais foram os efeitos desta crise no nível de vida de um determinado conjunto de trabalhadores portugueses, a partir da análise de dois casos específicos, designadamente, Lisboa e Coimbra e, por outro, situar o caso português no contexto atrás descrito. Embora a relação entre preços e salários seja um tema central da história económica internacional ${ }^{4}$, a historiografia portuguesa não se debruçou ainda sobre esta questão em concreto, o que justifica a pertinência deste trabalho.

Este artigo resulta da recolha de dados, no âmbito do projecto Prices, Wages and Rents in Portugal (1500-1900) ${ }^{5}$, nomeadamente, de preços dos

1 Este trabalho teve como origem uma comunicação apresentada pelo autor e por Ana Margarida Dias da Silva no XXX Encontro da Associação Portuguesa de História Económica e Social. Assim, o primeiro e principal agradecimento é-lhe dirigido. Gostaria ainda de agradecer a toda a equipa do Prices Wages and Rents in Portugal (1500-1900) e, sobretudo, ao Doutor Jaime Reis e à Doutora Conceição Andrade Martins. Por último devo um também especial agradecimento à Dra. Ana Isabel Silva, à Doutora Susana Münch Miranda, ao Doutor Rui Faísca Pereira, ao Duarte e aos dois referees anónimos que avaliaram este artigo.

2 ALLEN, Robert C. - The Great Divergence in European Wages and Prices from the Middle Ages to the First World War. Explorations in Economic History, 38 (2001), 411-447; VAN ZADEN, Jan - Wages and the Standard of Living in Europe, 1500-1800. European Review of Economic History. 3 (1999) 175-198.

3 Fenómeno que Robert C. Allen designou como a "Grande divergência" nos salários e preços europeus, em ALLEN, Robet C. - The Great..., cit.

4 ALLEN, Robert C. - The Great..., cit., p. 411.

5 Projecto acolhido pelo Instituto de Ciências Sociais da Universidade de Lisboa, financiado pela Fundação para a Ciência e a Tecnologia, coordenado pelo Doutor Jaime Reis e com a colaboração das Doutoras Conceição Andrade Martins e Leonor Freire Costa em Lisboa, do Doutor Álvaro Santos Pereira em Coimbra e da Doutora Inês Amorim no Porto. 
principais bens de consumo, de salários de trabalhadores especializados do sector da construção civil e, por último, de salários de trabalhadores indiferenciados. A primeira parte deste trabalho contempla exclusivamente questões de método, às quais se segue uma caracterização da evolução política e do desempenho económico e demográfico português durante a centúria de seiscentos, bem como das cidades alvo do nosso estudo. A segunda debruça-se sobre a evolução dos níveis de vida em ambas as cidades ao longo do século XVII.

Por último, concluímos que embora não tenha existido uma tendência sistemática e constante, no final do século XVII os trabalhadores das cidades de Lisboa e Coimbra possuíam um poder de compra consideravelmente mais baixo que os seus antepassados cem anos antes. Verificámos ainda que não existiu uma tendência divergente entre a capital portuguesa e a cidade universitária, não obstante a considerável diferença de dimensão e de volume comercial, fenómeno que, aliado a uma forte correlação na evolução dos preços, sugere a possibilidade de integração dos dois mercados.

Gostaríamos de ter à nossa disposição não só um maior número, como também uma maior variedade de dados, eliminando assim algumas limitações que a sua falta nos impôs. A primeira delas, de carácter qualitativo, prende-se com a constituição de um cabaz fixo de bens de consumo para cada cidade, quando procurámos obter uma aproximação daquilo que seriam os salários reais. Embora cada índice de preços tenha uma composição igual, nenhum dos cabazes contempla quaisquer gastos com o vestuário e com a habitação, o que também impede a obtenção de maior precisão sobre o valor dos salários reais. Procurando compensar esta limitação, como demonstraremos, majorámos os respectivos índices. Por outro lado, existem algumas falhas temporais nas nossas séries: por exemplo, ao nível dos preços, para um período de 100 anos, conseguimos não mais do que 63 observações em Lisboa e 57 em Coimbra, e, quanto aos salários de trabalhadores especializados, não reunimos observações para 21 e 14 anos respectivamente.

\section{Método}

Inserida no projecto Prices, Wages and Rents in Portugal (1500-1900), a recolha de dados efectuou-se essencialmente a partir de livros 
de receita e despesa de diversas instituições lisboetas e conimbricenses, que nos permitiram reunir várias dezenas de milhares de registos de preços dos principais bens de consumo (milho, trigo, centeio, carne de vaca e porco, galinha, ovos, azeite, vinho, carvão, etc.), bem como de salários de trabalhadores especializados e indiferenciados (pedreiros, carpinteiros, servidores, trabalhadores, pintores, escultores, médicos, enfermeiros, entre outros).

Os salários que aqui apresentamos correspondem a ocupações pagas à jorna, isto é, diariamente. Dentro desta lógica, recolhemos dados salariais de trabalhadores especializados ligados à indústria da construção, como carpinteiros, pedreiros, canteiros, pintores, etc., e de trabalhadores indiferenciados que realizavam todo o tipo de tarefas físicas, referidos nas fontes como "trabalhador", "servidor" ou simplesmente "homem". Procurámos, deste modo, evitar analisar profissões que tivessem, associados ao vencimento, determinados benefícios concedidos pelo empregador e que dificilmente se poderiam contabilizar. Por exemplo, é comum surgirem nas fontes, para profissões como físico ou cirurgião, benefícios como a oferta do arrendamento de uma habitação cujo preço de mercado não é referido, ou pagamentos em géneros pouco especificados, como um quarto de carneiro ou três quartos de porco. A reforçar esta nossa opção surgem ainda outras duas vantagens, por um lado, a sua grande homogeneidade no tempo e no espaço ${ }^{6}$ e, por outro, a sua recorrente utilização pela historiografia internacional.

Em relação aos fundos documentais consultados, procurámos cruzar várias fontes seleccionando preferencialmente instituições cujos arquivos permitissem, tanto quanto possível, estabelecer séries de longa duração temporal para que as fontes pudessem ser comparadas com as de outros espaços geográficos. Em Lisboa, consultámos, no Arquivo Nacional da Torre do Tombo, os seguintes fundos e sub-fundos documentais: Hospital de São José, Livros de Receita e Despesa do Hospital de Todos os Santos, Livros da casa da Inquisição de Lisboa, Livros de Receita e Despesa do Convento de Nossa Senhora da Luz de Lisboa e Livros de Despesa do Hospital da Luz.

6 DE VRIES, Jan - How did pré-industrial markets function in GRANTHAM, George and MACKINNON, Mary (ed.) - Labour Market evolution: the economic history of market integration, wage flexibility, and the employment relation. London: Routledge, 1994, p. 44. 
Consultámos ainda o fundo documental da Santa Casa da Misericórdia de Lisboa, disponível no Arquivo Histórico da instituição, sendo examinada a secção Livros de Receita e Despesa do Recolhimento dos Órfãos, da série Gestão Financeira.

Em Coimbra, a investigação centrou-se primordialmente no Arquivo da Universidade de Coimbra, onde foram consultados Livros de Receita e Despesa do Hospital de São Lázaro, as Obras da Universidade de Coimbra, Livros de Receita e Despesa do Hospital Real de Coimbra, Livros de receita e despesa da Obra da Igreja da Sé de Coimbra, Livros do Celeiro do Cabido da Sé de Coimbra e Livros da Superintendência da Cozinha do Colégio de S. Pedro. No Arquivo Histórico Municipal consultámos os livros de Receita e Despesa da Câmara e no Arquivo da Santa Casa da Misericórdia de Coimbra foram vistos os Livros do celeiro e os Livros de Receita e Despesa do Provedor.

Os dados recolhidos foram inseridos numa base de dados própria, dividida em registo de preços e salários. Os preços e os salários encontravam-se expressos segundo o sistema de pesos e medidas vigente à época. Para os podermos trabalhar de forma coerente, foi necessário efectuar dois exercícios, por um lado resolver o problema metrológico e, por outro, constituir um cabaz fixo de bens de consumo.

Deste modo, em primeiro lugar, procedeu-se à transposição dos dados expressos através do sistema de pesos e medidas do antigo regime (essencialmente em arráteis, alqueires e almudes) para o actual sistema métrico decimal. Para tal, foram utilizadas as tabelas elaboradas no século XIX pela Comissão Central de Pesos e Medidas, que estabeleceu a equivalência entre os dois sistemas para todos os concelhos do Reino ${ }^{7}$.

O cabaz de consumo escolhido para ambas as cidades é uma adaptação do utilizado para Estrasburgo em meados do século XVIII, por Robert Allen, com algumas modificações tendo em conta os dados disponíveis e a dieta alimentar mediterrânica ${ }^{8}$. Corresponde a 1941 calorias diárias, que o autor identifica como o patamar mínimo de bem-estar, abaixo do qual um

7 SILVEIRA, Joaquim Fradesso da - Mappas das medidas do novo systema legal: comparadas com as antigas nos diversos concelhos do reino e ilhas. Lisboa: Imprensa Nacional, 1868.

8 ALLEN, Robert C. - The Great..., cit., p. 421. 
homem entra em situação de carência alimentar. Os cabazes que construímos abrangem seis produtos com a seguinte distribuição: pão de trigo (49\%), carne $(14 \%)$, ovos $(2,2 \%)$, galinhas $(5,9 \%)$, vinho $(17,4 \%)$, azeite $(5,3 \%)$ e carvão (6,1\%). Ficaram em falta, por escassez de dados, alguns componentes do cabaz utilizado pelo historiador britânico, pelo que só temos $82,8 \%$ da sua composição. Foi por este motivo que majorámos os nossos resultados em cerca de $17 \%$, percentagem onde se incluem também despesas com a habitação, que se tem estimado situarem-se entre 5 e 10\% ${ }^{9}$. De acordo com os salários que seleccionámos, os produtos incluídos nos índices construídos absorveriam a larga maioria do rendimento disponível ${ }^{10}$. Desta forma, o Índice de Preços no Consumidor elaborado era responsável por grande parte da procura efectiva dos trabalhadores estudados.

\section{O século XVII em Portugal: época de crise e recessão}

O século XVII é caracterizado como um período de grave recessão económica na Península Ibérica, por oposição ao crescimento alcançado em algumas regiões da Europa Norte Atlântica. Para citar alguns exemplos, podemos referir que Fernand Braude ${ }^{11}$ e, posteriormente, outros autores, como Carlo Cippolla ${ }^{2}$, distinguem a recessão verificada no Sul da Europa de uma certa prosperidade alcançada pelos territórios situados junto ao Mar do Norte, onde se incluem, por exemplo, a Inglaterra, a Suécia ou a Holanda. Os estudos macroeconómicos mais recentes continuam, na globalidade, a suportar esta ideia ${ }^{13}$.

9 ALLEN, Robert C. - The British Industrial Revolution in Global Perspective. Cambrigde: University Press, 2009, p. 38.

${ }^{10}$ CIPPOLA, Carlo M - Before the industrial revolution: European society and economy, 1000-1700. London: Routledge, 1989, p. 182.

${ }^{11}$ BRAUDEL, Fernand - O tempo do mundo: Civilização material, Economia e Capitalismo: séculos XV-XVIII. Lisboa, Teorema: 1993.

${ }_{12}$ CIPPOLA, Carlo M - Before..., cit., p. 248-296.

${ }^{13}$ REIS, Jaime - "Economic Growth, Human Capital Formation and Consumption in Western Europe Before 1800" in ALLEN, Robert C.; BENGTSSON, Tommy and DRIBE, Martin (ed.) - Living Standards in the Past: New Perspectives on Well-Being in Asia and Europe. Oxford: Oxford University Press, 2005, p. 196-197. 
Quanto à historiografia nacional, de uma forma geral, divide o século XVII em três períodos, designadamente, um período de crescimento até aos anos de $1620^{14}$, ao que se segue um período de recessão de cerca de 70 anos - com especial ênfase nas décadas de 1670 a $1690^{15}$-, verificando-se nos últimos anos do século uma tendência de recuperação ${ }^{16}$.

De uma forma sumária, as causas mais citadas para a conjuntura económica em análise incluem a falta de um crescimento populacional contínuo após 1620, quando a população portuguesa terá atingido o seu máximo até então, seguindo-se um período de bastantes oscilações ${ }^{17}$, em sintonia com um fraco desempenho económico ${ }^{18}$, numa centúria recheada de instabilidade política e, consequentemente, de conflitos bélicos; alterações das condições climáticas; e uma destabilização geral em torno do Império.

De facto, com excepção dos últimos decénios, a centúria de seiscentos foi particularmente belicosa. Nos primeiros trinta anos, integrado na Monarquia Hispânica, Portugal viu-se envolvido em diversos conflitos na Europa e, sobretudo, nas colónias ultramarinas, contra as potências tradicionalmente opostas a "Espanha", como a Inglaterra ou a Holanda. Posteriormente, o não reconhecimento por Filipe III da proclamação da restauração da independência portuguesa, ocorrida em Lisboa a 1 de Dezembro de 1640, marcou o início de um período de guerra que se arrastaria por quase três décadas, terminando apenas em 1668. Pode dizer-se que, a partir daí, Portugal se manteve relativamente em paz até ao século XVIII.

${ }^{14}$ Veja-se, por exemplo, MATA, Eugénia da; VALÉRIO, Nuno - História Económica de Portugal: uma perspectiva global. $2^{\mathrm{a}}$ ed. Lisboa, Presença: 2002; SOUSA, Ivo Carneiro de - História de Portugal Moderno: economia e sociedade. Lisboa, Universidade Aberta: 1996; MENESES, Avelino de Freitas de - A Conjuntura Económica in MARQUES, A. H. de Oliveira e SERRÃO, Joel (coord.), Nova História de Portugal: do Renascimento à crise dinástica. Vol. VI. Lisboa: Presença, 1990, p. 213-381.

${ }^{15}$ SERRÃO, Joel Freitas de - A Conjuntura Económica in MARQUES, A. H. de Oliveira e SERRÃO, Joel (coord.), Nova História de Portugal: da contra-reforma à restauração. Vol VII. Lisboa: Presença, 1990, p. 213-381 e GODINHO, Vitorino Magalhães - Alguns problemas da economia portuguesa do século XVII de depressão internacional. Revista de História Económica e Social, 5 (1980), 105-123.

${ }^{16}$ MENESES, Avelino de Freitas de - A Conjuntura Económica..., cit.

17 SERRÃO, José Vicente - O quadro humano in MATTOSO, José (Dir.), História de Portugal: O Antigo Regime (1620-1817), Vol. 4. Lisboa: Círculo de Leitores, 1993, p. 51.

${ }^{18}$ MATA, Eugénia da; VALÉRIO, Nuno - História Económica de Portugal..., cit., p. 104-105. 
Toda esta turbulência política teve como consequência o aumento significativo das despesas da Coroa, sobretudo aquelas directamente relacionadas com o incremento da actividade militar. Para fazer face a estas novas exigências, durante este período, importantes medidas foram tomadas a nível fiscal e monetário. A carga fiscal aumentou consideravelmente e, desta forma, o século XVII assiste à criação de novos impostos, indirectos - o real da água, a meia-anata, o estanco do tabaco ou o papel selado, entre outros -e de um imposto directo, a décima. Dos primeiros, é necessário realçar o real da água, já que se trata do imposto que mais incide sobre bens de procura com uma elasticidade reduzida - carne, vinho, arroz, azeite, etc. Assim, o efeito de um imposto desta natureza pauta-se por um aumento do preço, absorvido essencialmente pelo consumidor devido à dificuldade deste em substituir o consumo de bens essenciais. Quanto à décima - tributo inspirado no dízimo eclesiástico - traduziu-se, inicialmente, na colecta da décima parte do rendimento e riqueza individuais. No entanto, consoante as necessidades financeiras da Coroa, o valor da tributação variou entre os $10 \%$ e os $4,5 \%$. De qualquer forma, os efeitos deste imposto na economia quotidiana traduziram-se certamente na redução do poder de compra individual.

Contudo, os impostos nem sempre se revelaram suficientes para garantir todas as crescentes despesas da Coroa. Esta recorreu também à manipulação do sistema monetário, através da desvalorização da moeda e, simultaneamente, do aumento da oferta monetária. Com os lucros decorrentes das contramarcações e recunhagens que estas medidas implicaram, vários monarcas portugueses, desde Filipe III a Pedro II, canalizaram recursos para a fazenda pública. A desvalorização da moeda por um lado e, por outro, o aumento da oferta monetária têm consequências inflacionistas que em muito podem comprometer o nível de vida caso os salários não acompanhem a subida de preços. Na realidade, muitos autores apontam manipulações do sistema monetário como a razão principal para períodos de alta inflação em sistemas monetários metálicos, tal como aquele que vigorava em Portugal no século XVII ${ }^{19}$. Em resumo, a intervenção da Coroa previsivelmente agravou as condições económicas e, ao mesmo tempo, o nível de vida das populações.

${ }^{19}$ EDVISSON, Rodney - Inflation before paper money: debasement cycles in Sweden (1350-1594). Scandinavian Economic History Review, 59 (2011) 166-190. 
O século XVII foi igualmente um período de grande agitação nas possessões ultramarinas portuguesas, tanto a Oriente como a Ocidente. De facto, a cronologia político-económica dos Estados da Índia e do Brasil - os dois principais domínios lusos ultramarinos - é semelhante à evolução económica nacional. Assim, no Brasil, a principal indústria, a do açúcar, vinha em crescendo desde a segunda metade do século anterior, atingindo o seu pico por volta dos anos de 1620, época a partir da qual o incremento da hostilidade com os Holandeses e a instabilidade dos preços marcaram décadas de declínio. A segunda metade do século também não foi brilhante, pois a concorrência comercial do açúcar das Antilhas teve como consequência uma baixa de preços daquele produto e, ao mesmo tempo, um aumento significativo do custo de mão-de-obra, isto é, do preço dos escravos. Por outro lado, uma vez mais, as necessidades de financiamento da Guerra da Restauração obrigaram a Coroa a taxar o comércio açucareiro, asfixiando ainda mais esta indústria. Na década de 1680, a economia açucareira tinha alcançado o seu nível mais baixo, do qual os mais pessimistas julgavam não ser possível sair. Porém, a guerra entre Inglaterra e França (1689-97) voltou a abalar o comércio atlântico e aumentou os preços dos produtos coloniais, pelo que a indústria luso-brasileira recuperou então parte da sua rentabilidade ${ }^{20}$.

Quanto ao Estado da Índia, embora em declínio se comparado com o que se verificara no século anterior, durante a primeira década de seiscentos o velho sistema de comércio de carreira conseguiu manter uma actividade considerável, não obstante a constante e crescente ameaça britânica e holandesa. Todavia, os anos de 1620 e 1630 foram um período de crise e de escassez financeira, com o alargamento da influência das potências do Mar do Norte no Oceano Índico, em parte à custa dos portugueses, que viram reduzir-se a sua presença no Oriente e, da mesma forma, o seu volume comercial. A partir dos anos de 1640, a competição entre as Companhias das Índias britânica e holandesa deixou uma certa margem de

\footnotetext{
${ }^{20}$ MAGALHÃES, Joaquim Romero - A construção do espaço brasileiro in BETHENCOURT, Francisco; CHAUDHURI, Kirti (dir.) - História da expansão portuguesa: Do Índico ao Atlântico (1570-1697). Vol. II. Lisboa: Círculo de Leitores, 1998, p. 26-64.
} 
manobra para uma pequena recuperação do comércio da carreira da Índia, ainda que a níveis inferiores aos do início do século ${ }^{21}$.

Em conclusão, economicamente, o século XVII foi para o Império português bastante problemático, com uma crise prolongada após um início de certa forma auspicioso - sobretudo no Brasil -, da qual só viria parcialmente a sair já no seu final.

Por último, a evolução demográfica também segue de perto a evolução política e económica, ou seja, nos primeiros anos do novo século o Reino mantém o crescimento populacional que se vinha a verificar desde finais da Idade Média, embora de forma cada vez menos intensa. A partir daqui, entra-se numa fase de recessão ou de estagnação e, em 1640, a população portuguesa estaria de novo ao nível de 1532. Apenas na última década de seiscentos os efectivos populacionais recuperam, ainda que mantendo um crescimento modesto.

\section{As cidades de Lisboa e Coimbra}

Lisboa era, no século XVII, a única cidade portuguesa de real dimensão europeia, com uma intensa actividade comercial nacional e internacional, fruto não só do seu movimentado porto marítimo, mas também de ligações terrestres e fluviais que permitiam a interacção com o interior do Reino. A capacidade de atracção de fluxos migratórios da capital estendia-se a todo o território nacional e inclusivamente a comunidades estrangeiras radicadas em Portugal; ambos os grupos privilegiavam Lisboa como local de imigração enquanto, por norma, a área geográfica de recrutamento populacional dos restantes centros urbanos lusos estava relacionada com a dinâmica da economia local, numa lógica de média/curta distância ${ }^{22}$.

${ }^{21}$ CHAUDHURI, Kirti - O comércio asiático in BETHENCOURT, Francisco; CHAUDHURI, Kirti (dir.) - História da expansão portuguesa: Do Índico ao Atlântico (1570-1697). Vol. II. Lisboa: Círculo de Leitores, 1998, p. 175.

${ }^{22}$ RODRIGUES, Teresa - As vicissitudes do povoamento nos séculos XVI e XVII in RODRIGUES, Teresa (coord.) - História da população portuguesa. Porto: Edições Afrontamento, 2009, p. 159-247. 
Muito embora a sua importância relativa no contexto europeu viesse já a decair desde o final do século anterior, Lisboa teria ainda uma população mais numerosa que, por exemplo, Sevilha nos anos 20 do século XVII, estimando-se que o número de habitantes da capital portuguesa se situasse entre os 120 e os 165 mil. Estes números colocam-na como a primeiríssima cidade do Reino, já que continha, em escassos $8 \mathrm{~km}^{2}$, quase um décimo da população nacional23.

O desempenho demográfico lisboeta variou bastante durante os cem anos que aqui analisamos. Ao que tudo indica, no primeiro quartel de seiscentos a população continuou a aumentar lentamente, a um ritmo de crescimento médio anual de apenas $0,33 \%{ }^{24}$, contrastando, por exemplo, com os $2 \%$ verificados no início do século XVI. Sensivelmente a partir dos anos de 1630 e até ao terceiro quartel do século, a estagnação e mesmo, por vezes, o crescimento negativo são o resultado do aumento global da mortalidade e do declínio da natalidade, por um lado; e, por outro, do número crescente de fogos vazios ou reduzidos, especialmente em relação ao género masculino, numa taxa de crescimento anual negativa de $-0,65 \%{ }^{25}$. No final do século XVII, Lisboa parece seguir a tendência nacional, com uma recuperação lenta mas progressiva dos efectivos populacionais, a rondar os $0,11 \%$ anuais ${ }^{26}$; valores que, no entanto, apenas permitiram repor a população, já que a capital só ultrapassaria os efectivos verificados no início de seiscentos já durante o século XVIII ${ }^{27}$ Por comparação com Lisboa, Coimbra era de dimensão bastante menor e, embora em crescimento, apenas contaria com uma população de cerca de 10 mil habitantes ${ }^{28}$, menos de um décimo da população lisboeta. Em meados do século XVI, Coimbra ocupava ainda um lugar pouco destacado no contexto urbano nacional, visto que sete núcleos urbanos - Lisboa, Porto, Guimarães, Santarém, Évora e Tavira

${ }^{23}$ RODRIGUES, Teresa - Crises de Mortalidade em Lisboa: Séculos XVI e XVII. Lisboa: Livros Horizonte, 1990.

${ }^{24}$ RODRIGUES, Teresa - As vicissitudes..., cit., p. 196.

${ }^{25}$ RODRIGUES, Teresa - As vicissitudes..., cit., p. 196.

${ }^{26}$ RODRIGUES, Teresa - As vicissitudes..., cit., p. 196.

${ }^{27}$ RODRIGUES, Teresa - Crises de Mortalidade..., cit.

${ }^{28}$ MATA, Eugénia da; VALÉRIO, Nuno - História Económica de Portugal..., cit., p. 1022-103. 
- seriam de maior dimensão ${ }^{29}$. Contudo, o estabelecimento definitivo da Universidade em Coimbra veio modificar o crescimento natural e real da população conimbricense. A população cresceu para perto dos referidos 10 mil habitantes permanentes, acrescidos de uma percentagem significativa de uma população académica flutuante. Os estudantes eram, sem quaisquer dúvidas, consumidores de bens e serviços e, por outro lado, acentuaram as ligações comerciais de Coimbra com as principais cidades do Reino.

A cidade universitária, situada numa região de transição, estava bem fornecida de meios de comunicação. Por um lado fluviais e, por extensão, marítimos, através da navegação no Rio Mondego desde a sua foz até sensivelmente à Senhora da Ribeira, a jusante de Coimbra, e de alguns dos seus afluentes - como é o caso do Rio Ceira. Por outro, terrestres, visto que a principal ligação Norte-Sul de Portugal passava por esta cidade onde, desde o período romano, existe uma ponte que, no século XVII, era das mais frequentadas do país ${ }^{30}$.

Embora com uma lógica comercial distinta de Lisboa, não participando de uma forma tão activa no comércio internacional ${ }^{31} \mathrm{e}$, assim, estando a sua estrutura económica mais dependente de factores locais ${ }^{32}$, Coimbra não era, de maneira alguma, uma cidade "isolada", o que se reflecte na percentagem relativamente elevada da população activa - cerca de 5\% - que, nesta época, desempenhava ofícios ligados aos transportes e comunicações tanto terrestres como fluviais ou, por exemplo, no facto de uma percentagem significativa dos seus residentes ser natural das províncias do Norte $^{33}$.

Perante a conjuntura adversa acima descrita, é lógico esperar uma queda acentuada dos níveis de vida em Lisboa e Coimbra, devido a uma quebra do rendimento individual, embora seja difícil prever a priori quais as diferenças de comportamento entre estas cidades, se é que estas são significativas.

${ }^{29}$ OLIVEIRA, António - A vida económica e social de Coimbra de 1537 a 1640. Coimbra: FLUC, 1971, p. 1-57.

${ }^{30}$ OLIVEIRA, António - A vida económica..., cit., p. 1-57.

${ }^{31}$ MENESES, Avelino de Freitas de - A Conjuntura Económica..., cit., p. 222.

${ }^{32}$ NUNES, Mário; COSTA, António Leite (coord.) - Coimbra na época moderna, a Universidade e a sua história. Coimbra: Câmara Municipal de Coimbra, 2009, p. 30.

${ }^{33}$ RODRIGUES, Teresa - As vicissitudes..., cit., p. 235. 


\section{Evolução dos níveis de vida}

Para analisar os níveis de vida em ambas as cidades, é necessário fazer uma aproximação aos salários reais, ou seja, calcular o quociente entre os salários monetários e o nosso Índice de Preços no Consumidor. O poder de compra de um indivíduo é determinado pela relação existente entre o rendimento de que dispõe e o custo dos bens de consumo e serviços que podem ser adquiridos com esse rendimento, encontrando-se ambos expressos em réis correntes. Nesse sentido, dividimos o valor dos cabazes anuais de Lisboa e Coimbra pelo resultado da multiplicação do vencimento diário de um trabalhador pelo número de dias de trabalho anual.

Dispomos de várias estimativas para este último número. Uma é dada por Isabel dos Guimarães Sá34, que se baseia nas Constituições Sinodais, e apura para a cidade de Lisboa 272,5 dias de trabalho no século XVII e 282 dias de trabalho para Coimbra no século XVIII. Uma fonte coeva, de meados do século XVI, refere que, em Lisboa, pedreiros, canteiros e carpinteiros, com os seus respectivos serventes, trabalhadores e criados, trabalhariam 270 dias por ano ${ }^{35}$. Porém, optámos pelos 250 dias utilizados por Robert Allen ${ }^{36}$, de forma a podermos manter um padrão de comparação internacional, e também pelo facto deste número contemplar algum absentismo por parte do trabalhador, por exemplo, se tiver algum problema de saúde.

Finalmente, e seguindo, uma vez mais, o método do historiador britânico, efectuámos ainda uma multiplicação de cada cabaz por 3,15, que corresponde à inclusão das despesas de um agregado familiar composto por uma mulher e duas crianças. Esta nossa opção deve-se à aceitação do padrão utilizado por Robert Allen de forma a tornar o nosso trabalho comparável internacionalmente, mas também devido a uma certa escassez de dados sobre o valor pecuniário do trabalho feminino e, sobretudo, do trabalho a que contemporaneamente designamos de trabalho infantil. No entanto,

${ }^{34}$ SÁ, Isabel dos Guimarães - O Trabalho in SILVA, Álvaro Ferreira da; LAINS, Pedro (org.), História Económica de Portugal: 1700-2000. Vol. I. Lisboa, Imprensa de Ciências Sociais, 2005, p. 114.

${ }^{35}$ BRANDÃO, João - Grandeza e abastança de Lisboa em 1552. Lisboa: Livros Horizonte, 1990 [1552].

${ }^{36}$ ALLEN, Robert C. - The British Industrial Revolution..., cit., p. 38. 
não queremos deixar de assinalar a contribuição do trabalho feminino para a economia familiar ${ }^{37}$ que, aliás, seria mais relevante à medida que se desce na escala social ${ }^{38}$.

Antes de analisarmos com maior detalhe os níveis de vida, cremos ser necessário assinalar a distinção de movimentos entre salários e preços. Desta forma, através da observação do Gráfico 1, podemos, desde logo, concluir que os valores dos salários nominais que recolhemos se caracterizam pela sua estabilidade, não sofrendo grandes variações ao longo deste século; quando se alteram, o seu valor raramente decresce, ou seja, não existem quedas nominais do rendimento do trabalho. Esta tendência tem sido identificada com frequência para outras regiões da Europa por bastantes autores $^{39}$. Como seria de esperar, o mesmo não se aplica aos preços, assinalando-se grandes variações anuais, pois na economia pré-industrial era bastante comum verificar-se uma forte variância ao nível dos preços, com especial foco nos produtos alimentares que constituem grande parte do nosso cabaz, devido às condições em que ocorriam as colheitas, ao modo como funcionava, num determinado período, a cadeia de distribuição e à existência de conflitos bélicos ${ }^{40}$.

Perante esta realidade, as variações dos níveis de vida dever-se-ão em muito maior medida ao comportamento dos preços do que à situação salarial dos trabalhadores

${ }^{37}$ ALLEN, Robert C. - The British Industrial Revolution..., cit, p. 40; BOULTON, Jeremy - Wage labour in seventeenth-century London. The Economic History Review, 49, (1996), p. 284.

${ }^{38}$ MOTA, Guilhermina - O trabalho feminino e o comércio em Coimbra (sécs. XVII e XVIII). Actas do Colóquio Coimbra, 20 a 22 Março 1985. Coimbra: Instituto de História Económica e Social, Faculdade de Letras, 1986, p. 351.

${ }^{39}$ Entre os quais Karl Persson em PERSSON, Karl - An economic history of Europe: knowledge, institutions and growth, 600 to the present. Cambridge: Cambridge University Press, 2010; Jan de Vries em DE VRIES, Jan - How did pré-industrial markets function in GRANTHAM, George and MACKINNON, Mary (ed.) - Labour Market evolution: the economic history of market integration, wage flexibility, and the employment relation. London: Routledge, 1994, p. 39-64; Douglas Fisher e Lee Craig em CRAIGH, Lee; FISHER, Douglas - The European Macroeconomy: Growth, Integrations and Cycles, 1500-1913. Cheltenham: Edward Elgar, 2000.

${ }^{40}$ PAMUK, Sevket - Real Wages and the Standards of Living in the Ottoman Empire, 14629-1914. The Journal of Economic History. 62 (2002), p. 299. 


\section{Gráfico 1 - Salários diários nominais durante o século XVII (Lisboa e Coimbra)}

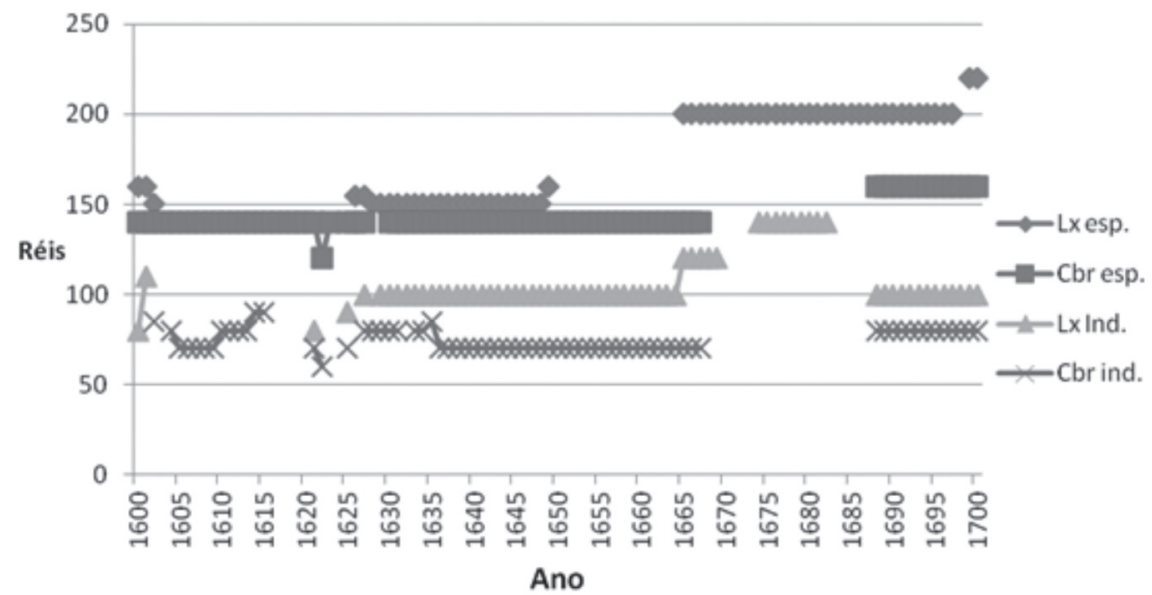

Fonte: Elaboração Própria

Regressando à análise dos níveis de vida, verifica-se assim que a sua evolução no século XVII pautou-se por uma tendência negativa, isto é, de degradação dos níveis de vida em ambas as cidades e em ambos os tipos de trabalhadores, tal como está expresso nos Gráficos 2 e 3 . Considerando este indicador como uma variável dependente da função tempo, obtivemos todos os coeficientes de regressão negativos, o que reforça de forma quantitativa a afirmação anterior.

Quadro 1 - Coeficiente de regressão entre o nível de vida (variável dependente) e o tempo

\begin{tabular}{|c|c|c|}
\hline Trabalhador & Lisboa & Coimbra \\
\hline Especializado & $-0,0023$ & $-0,0088$ \\
\hline Indiferenciado & $-0,0026$ & $-0,0060$ \\
\hline
\end{tabular}

Fonte: Elaboração Própria

Contudo, esta tendência secular esconde diversas variações de curto prazo, significativamente mais marcadas em Lisboa, as quais podem ser novamente verificadas nos Gráficos 2 e 3, ou constatadas pela fraca correlação entre o tempo e o índice de nível de vida para a capital, que demonstra não estarmos perante um decréscimo contínuo, pois, se assim fosse, aquela seria bem mais acentuada, situando-se num valor mais próximo 
da correlação absoluta. Já para os trabalhadores de Coimbra, a tendência negativa foi mais constante, uma vez que a correlação entre o tempo e o índice de nível de vida respectivo é mais expressiva e, ao mesmo tempo, as variações foram de menor amplitude, como podemos verificar através do Coeficiente de variação expresso no Quadro 3.

Quadro 2 - Coeficiente de Correlação de Pearson entre o nível de vida e o tempo

\begin{tabular}{|c|c|c|}
\hline Trabalhador & Lisboa & Coimbra \\
\hline Especializado & $-0,38$ & $-0,70$ \\
\hline Indiferenciado & $-0,43$ & $-0,77$ \\
\hline
\end{tabular}

Fonte: Elaboração Própria

Quadro 3 - Coeficiente de variação do nível de vida em Lisboa e Coimbra

\begin{tabular}{|c|c|c|}
\hline Coef. Var. & Lisboa & Coimbra \\
\hline Especializados & 7,56 & 4,35 \\
\hline Indiferenciados & 5,61 & 3,59 \\
\hline
\end{tabular}

Fonte: Elaboração Própria

Gráfico 2 - Níveis de vida em Lisboa (século XVII)

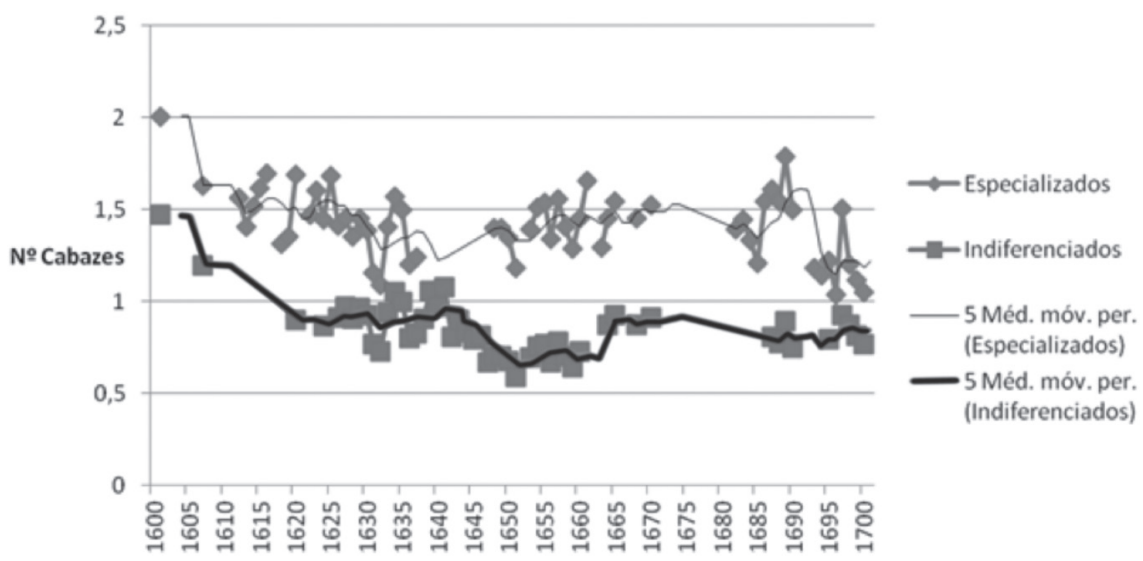

Fonte: Elaboração Própria

Como já referimos, as grandes variações representadas nos Gráficos 2 e 3 correspondem sobretudo às constantes variações do Índice de Preços, já que os salários sofrem menores alterações. Estas flutuações são especialmente fortes em meados do século, o que talvez se deva a algum efeito relacionado 
Gráfico 3 - Níveis de vida em Coimbra (século XVII)

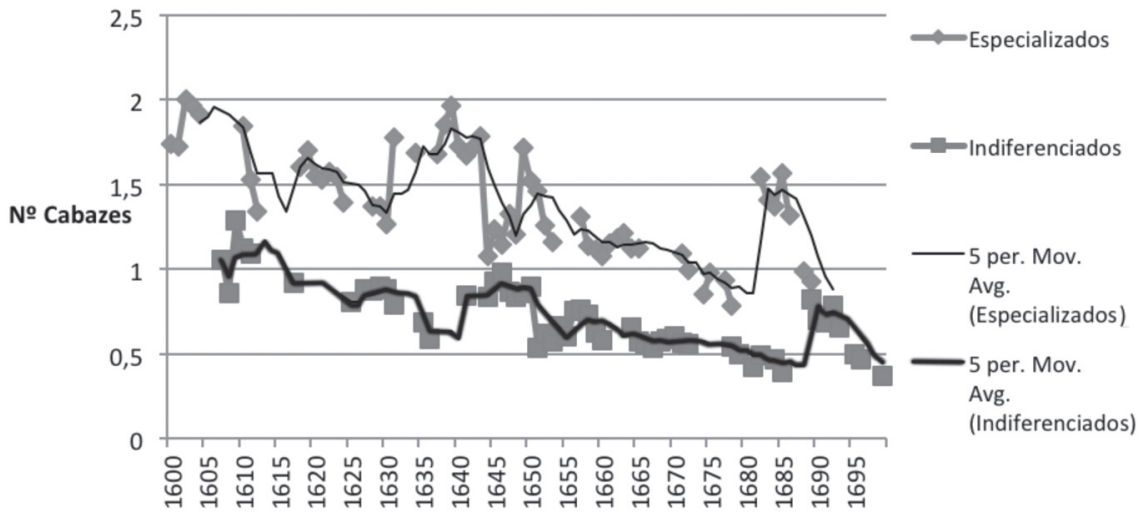

Fonte: Elaboração Própria

com a Guerra da Restauração. A falta de dados das décadas de 1670 e 1680 deixa por explicar uma aparente subida dos salários reais atingida em meados desta última. O que podemos afirmar com mais certeza é que não existiu, considerando toda a série secular, um aumento de nenhum dos salários reais durante o século XVII e, na realidade, na década de 1690, acabam por diminuir significativamente, encerrando-se a centúria com os trabalhadores portugueses a usufruir de um poder de compra significativamente mais reduzido do que os seus antecessores do início do século.

A tendência verificada nos níveis de vida portugueses é semelhante à que tem sido constantemente verificada por outros autores para o resto do continente europeu, com excepção da Holanda, da Inglaterra e de algumas cidades de outros países. Nestes locais, pelo contrário, presenciou-se uma economia de "salários altos", com particular foco, a partir do século XVIII, em Inglaterra, sendo este factor apontado por Robert Allen como uma das principais causas da Revolução Industrial Britânica ${ }^{41}$. De qualquer forma, em algumas cidades europeias, tais como Madrid, Barcelona, Paris e Varsóvia ${ }^{42}$,

${ }^{41}$ Para uma explicação detalhada ver ALLEN, Robert C. - The British Industrial Revolution...,cit.

${ }^{42}$ ALLEN, Robet C. - The Great..., cit., p. 430. Para o caso catalão ver FELIU, GasparPrecios y salarios en la Cataluña moderna: vol II: combustibles, productos manufacturados y salarios. [Madrid]: Banco de España, Servicio de Estudios, 1991. 
os salários reais não caíram, mantendo-se num nível superior ao verificado na capital portuguesa.

Lisboa não se diferenciou especialmente de Coimbra, com a queda e/ou a estagnação do valor dos salários reais a traduzir-se por um poder de compra baixo, frequentemente inferior ao padrão mínimo de bem-estar estabelecido, no caso dos trabalhadores indiferenciados. A semelhança dos resultados levanta a possibilidade da integração dos dois mercados já que, conforme se pode verificar no Gráfico 4, a variação dos respectivos índices de preços parece ter alguma simetria.

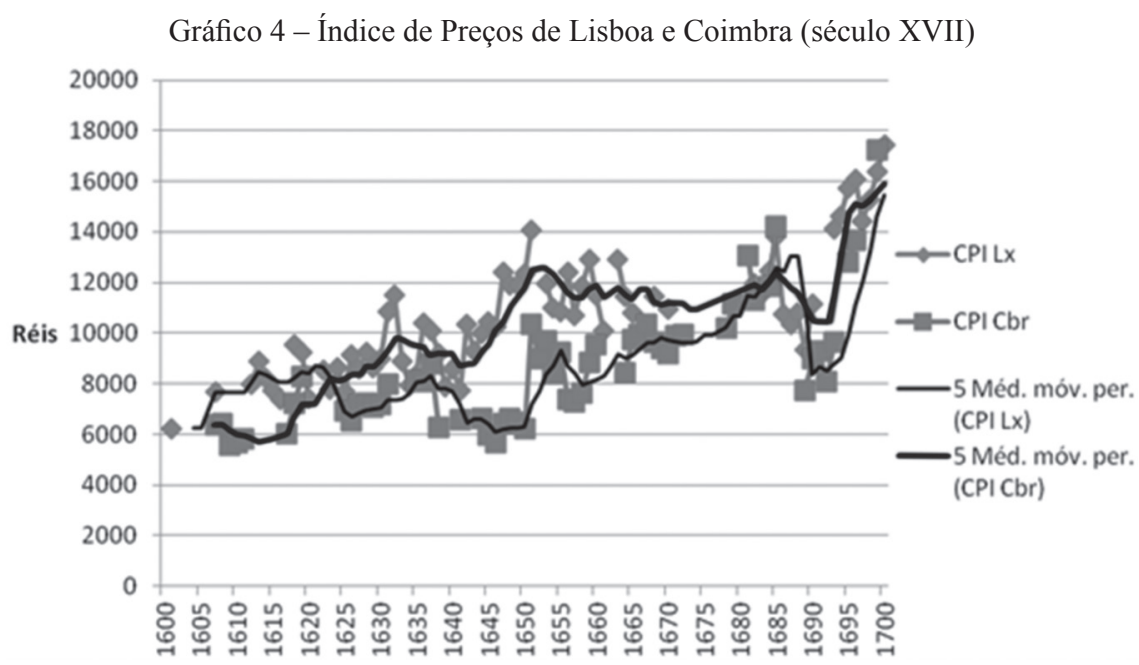

Fonte: Elaboração Própria

A fortalecer esta ideia surge uma forte correlação positiva entre os preços das duas cidades ${ }^{43}$ e, simultaneamente, embora em menor medida, um coeficiente de determinação não desprezível da regressão linear que pressupõe o índice de preços em Lisboa como variável independente ${ }^{44}$. Porém, a determinação da integração do mercado interno português do século XVII ultrapassa os objectivos deste artigo e, para chegar a essa conclusão, seriam necessários mais exemplos regionais.

${ }^{43}$ O Coeficiente de correlação de Pearson entre os dois índices é de 0,68.

${ }^{44} \mathrm{O}$ Coeficiente de determinação da regressão linear em que a variável independente é o IPC de Lisboa é de 0,47 . 


\section{Conclusão}

A principal conclusão a retirar deste estudo é a de que durante o século XVII ocorreu uma quebra dos níveis de vida não só nas duas cidades de Lisboa e Coimbra, como também nos dois tipos de trabalhadores (especializados e não especializados) que analisámos. Esta quebra, todavia, não foi constante, sofrendo diversas variações no curto prazo, mais frequentes no caso lisboeta. Em concreto, podemos afirmar que esta situação se deveu principalmente ao facto de os salários não acompanharem as oscilações de preços e, desta forma, a tendência secular de inflação que se verificou traduziu-se numa redução considerável do poder de compra destes trabalhadores. Assim, podemos concluir que, pelo menos durante o século XVII, o nível de vida português seguiu de perto a tendência negativa da maioria dos países europeus, divergindo dos líderes do Mar do Norte.

Outro aspecto a salientar é o comportamento semelhante não só dos níveis de vida de Lisboa e Coimbra, mas sobretudo do índice de preços, o que sugere a possibilidade dos dois mercados estarem integrados entre si.. 